\title{
PHOTOELASTIC ANALYSIS OF CRACKED THICK WALLED CYLINDERS
}

\author{
PASTRAMĂ Stefan Dan \\ Professor, Faculty of Engineering and Management of Technological Systems/Department of Strength of \\ Materials, University POLITEHNICA of Bucharest, Romania, e-mail: stefan.pastrama@upb.ro
}

\begin{abstract}
In this paper, the experimental determination of the stress intensity factor in thick walled cylinders subject to uniform internal pressure and having longitudinal non-penetrating cracks is presented. Photoelastic measurements were used together with the expressions of the stress field near the crack tip for Mode I crack extension and a specific methodology for stress intensity factor determination. Two types of longitudinal cracks - internal and external - were considered. Four plane models were manufactured and analyzed in a plane polariscope at different values of the applied internal pressure. The values of the normalized stress intensity factor were calculated and the results were compared to those reported by other authors. A good accuracy was noticed, showing the reliability of the experimental procedure.
\end{abstract}

Key words: Crack, Stress intensity factor, Photoelasticity, Isochromatic fringes

\section{Introduction}

The computation of the stress intensity factor (SIF) at the tip of a crack is possible if one knows the stress field near the crack tip. In the scientific literature, many analytical, numerical and experimental methods were developed for this purpose. From the experimental methods, photoelasticity proved to be a very reliable one, and many scientists devoted their efforts to improve the photoelastic computation of the stress intensity factor.

Etheridge and Dally [1] made a comparative analysis of several methods for the determination of the stress intensity factor based on the analysis of the isochromatic fringes in the region surrounding the crack tip. All these methods use the experimental data obtained from only one or two fringes. Irwin [2] used the equations of the stress field near the crack tip for Mode I to calculate the stress intensity factor from a single fringe data. Bradley and Kobayashi [3] modified the method of Irwin by using the values of the fringe order from two consecutive fringes. Schroedel and Smith [4] proposed the calculation of the stress intensity factor using the values of the fringe order on a line normal to the crack tip, method which was subsequently developed by Smith [5]. A methodology similar to that proposed in [3] was developed by Etheridge and Dally [6], which introduced a correction factor for the boundary effects in the expressions of the stress intensity factor. Chona et al. [7] used the Westergaard stress field expressions, written as series expansion and obtained the coefficients of the expansion using photoelastic data. Sanford and Dally [8] and Sanford [9-11] used photoelastic data in an iterative scheme based on the least square method and the Newton-Raphson procedure to obtain the stress intensity factor for a mixed Mode I + II. Their procedure was used in practical cases by Hyde and Warrior [12] and Mahinfalah and Zackery [13]. A similar overdeterministic algorithm based on photoelastic data was proposed by Stepanova et al. [14] to assess the complete Williams series coefficients of the linear elastic stress field in the vicinity of the crack tip for a wide class of experimental specimens subject to mixed mode loading: edge cracked semi-circular disk specimen, plates with two collinear cracks under tensile loading, pure shear loading and mixed mode loading. Patil et al. [15] proposed a linear least square approach to estimate the mixed-mode crack tip fracture parameters by solving the multi-parameter stress field equation. The stress intensity factor was extracted from the estimated fracture parameters, calculated using isochromatic and isoclinic data around the crack tip obtained by the ten-step phase shifting technique. The method of Irwin [2] was used by Umezaki et al. [16] to determine the stress intensity factor in an epoxy resin plate with lateral crack under 3-point bending, using isochromatics multiplied and extracted from original isochromatic images obtained from a white light photoelastic experiment. Experimental measurements using photoelasticity were performed by Cirello et al. [17] in order to validate a numerical procedure, which combines two hybrid finite element formulations, for the stress intensity factor determination in cracked perforated plates with a 
periodic distribution of holes and square representative volume elements. A new method for calculating stress intensity factors was proposed by Diaz et al. [18]. They analyzed a data array calculated from two photoelastic images and emphasized that it is possible to obtain accurate results in a few seconds by capturing only the light- and dark-field images from a circular polariscope.

In this paper, the stress intensity factor in a thick walled cylindrical shell subject to a uniform internal pressure and having a straight non-penetrating longitudinal crack is calculated by bidimensional photoelasticity. The experimental results are processed using the method proposed in [5]. In order to validate the obtained results, the values of the experimentally obtained stress intensity factor were compared to those reported by other authors.

\section{Methodology}

The global field equations for the stress components for a straight front crack under mode I conditions in an infinite plate can be written in the form [19]:

$$
\begin{aligned}
\sigma_{x}= & \frac{K}{\sqrt{8 \pi r}} \cos \frac{\theta}{2}\left(1-\sin \frac{\theta}{2} \sin \frac{3 \theta}{2}\right)+\sigma_{0 x}+ \\
& +\sum_{n=3}^{\infty}\left(A_{n} \frac{n}{2}\right) r^{\frac{n}{2}-1}\left\{\left[2+(-1)^{n}+\frac{n}{2}\right] \cos \left(\frac{n}{2}-1\right) \theta-\left(\frac{n}{2}-1\right) \cos \left(\frac{n}{2}-3\right) \theta\right\} \\
\sigma_{y}= & \frac{K}{\sqrt{8 \pi r}} \cos \frac{\theta}{2}\left(1+\sin \frac{\theta}{2} \sin \frac{3 \theta}{2}\right)+ \\
& +\sum_{n=3}^{\infty}\left(A_{n} \frac{n}{2}\right) r^{\frac{n}{2}-1}\left\{\left[2-(-1)^{n}-\frac{n}{2}\right] \cos \left(\frac{n}{2}-1\right) \theta-\left(\frac{n}{2}-1\right) \cos \left(\frac{n}{2}-3\right) \theta\right\} \\
\tau_{x y}= & \frac{K}{\sqrt{8 \pi r}} \sin \frac{\theta}{2} \cos \frac{\theta}{2} \cos \frac{3 \theta}{2}- \\
& -\sum_{n=3}^{\infty}\left(A_{n} \frac{n}{2}\right) r^{\frac{n}{2}-1}\left\{\left[(-1)^{n}+\frac{n}{2}\right] \sin \left(\frac{n}{2}-1\right) \theta-\left(\frac{n}{2}-1\right) \sin \left(\frac{n}{2}-3\right) \theta\right\}
\end{aligned}
$$

where $(r, \theta)$ are the polar coordinates in a system of axes having the origin at the crack tip (Figure 1). The constant term $\sigma_{0 x}$ in the expression of $\sigma_{x}$ was introduced by Irwin [2] which observed that, when an extending crack moves across a plate of finite width, at a certain length the stress field equations (1) may not be accurate and a correction needs to be applied for a finite body.

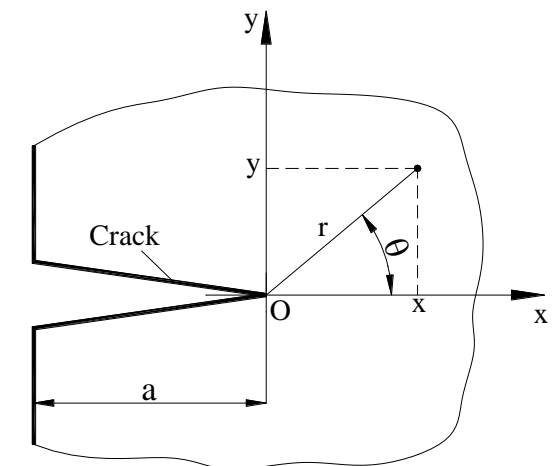

Figure 1: The system of axes

If the measurement zone is close enough to the crack tip, the first term in equations (1) is dominant, e.g. the other terms become negligible, except the constant term $\sigma_{0 x}$. In this case, one can write: 


$$
\begin{aligned}
\sigma_{x} & =\frac{K_{I}}{\sqrt{2 \pi r}} \cos \frac{\theta}{2}\left(1-\sin \frac{\theta}{2} \sin \frac{3 \theta}{2}\right)+\sigma_{0 x} \\
\sigma_{y} & =\frac{K_{I}}{\sqrt{2 \pi r}} \cos \frac{\theta}{2}\left(1+\sin \frac{\theta}{2} \sin \frac{3 \theta}{2}\right) \\
\tau_{x y} & =\frac{K_{I}}{\sqrt{2 \pi r}} \sin \frac{\theta}{2} \cos \frac{\theta}{2} \cos \frac{3 \theta}{2}
\end{aligned}
$$

Smith [5] proposed the evaluation of the order of the isochromatic fringes on a line normal to the crack front, that is $\theta=\pi / 2$, following his observations that the Mode I fringe patterns tend to spread in a direction approximately normal to the crack surface, expecting thus the best accuracy of the fringe along this direction. Rewriting equations (2) for $\theta=\pi / 2$, one obtains:

$$
\sigma_{x}=\frac{\sqrt{2}}{4} \frac{K_{I}}{\sqrt{2 \pi r}}+\sigma_{0 x} ; \sigma_{y}=\frac{3 \sqrt{2}}{4} \frac{K_{I}}{\sqrt{2 \pi r}} ; \tau_{x y}=-\frac{\sqrt{2}}{4} \frac{K_{I}}{\sqrt{2 \pi r}}
$$

The maximum shear stress in the points lying on the above mentioned line can be calculated using the well-known equation from theory of elasticity:

$$
\tau_{\max }=\frac{1}{2}\left(\sigma_{1}-\sigma_{2}\right)=\frac{1}{2} \sqrt{\left(\sigma_{x}-\sigma_{y}\right)^{2}+4 \tau_{x y}^{2}}
$$
form:

Using the results from equation (3), the expression of the maximum shear stress can be put in the

$$
\tau_{\max }=\frac{A}{\sqrt{r}}+B
$$

in which $A=K_{I} / \sqrt{8 \pi}$ and $B$ is a constant. On the other hand, $\tau_{\max }$ can be calculated using the photoelastic data as:

$$
\tau_{\max }=\frac{N \cdot f_{\sigma}}{2}
$$

where $N$ is the fringe order in a certain point and $f_{\sigma}$ is the photoelastic constant of the model. Normalizing equation (5) with $\sigma \sqrt{\pi a}$ and denoting $K_{a p p}=\tau_{\max } \sqrt{8 \pi r}$ as the apparent stress intensity factor, one obtains

$$
\frac{K_{a p p}}{\sigma \sqrt{\pi a}}=\frac{K_{I}}{\sigma \sqrt{\pi a}}+\frac{B \sqrt{8}}{\sigma} \sqrt{\frac{r}{a}}
$$

in which $\sigma$ is the load parameter, which, for the studied structure is the uniform pressure $p$ acting on the internal wall of the tube. From equation (5), valid under the assumptions of linear elastic fracture mechanics (outside the nonlinear zone at the crack tip), one can notice a linear variation of the normalized apparent stress intensity factor $K_{a p p} /(\sigma \sqrt{\pi a})$ with the non-dimensional parameter $\sqrt{r / a}$. Thus, in a set of photoelastic data, one needs to identify the linear zone and extrapolate this line across the nonlinear zone to the crack tip in order to obtain the value of the normalized stress intensity factor. Smith [20] emphasizes that the accuracy of the method depends on the ability of the experimentalist to locate the linear zone and suggests that this zone may be found for $\sqrt{r / a}$ greater than 0.4 and up to 0.7 or more.

\section{Experimental procedure}

Photoelastic experiments were made on four circular rings, having a radial non-penetrating crack, as plane models of a tube with a straight longitudinal crack. The dimensions of the models together with the applied internal pressure, are presented in

Table 1. 
ACTA UIVERSITATIS CIBINIENSIS - TECHNICAL SERIES

Vol. LXIX 2017

Table 1- Geometry of the models and the applied loads

\begin{tabular}{|c|c|c|c|c|c|c|c|}
\hline $\begin{array}{c}\text { Model } \\
\text { no. }\end{array}$ & Crack type & $\begin{array}{c}\text { External } \\
\text { radius } \\
\boldsymbol{R}_{\boldsymbol{e}}[\mathbf{m m}]\end{array}$ & $\begin{array}{c}\text { Internal } \\
\text { radius } \\
\boldsymbol{R}_{\boldsymbol{i}}[\mathbf{m m}]\end{array}$ & $\boldsymbol{R}_{\boldsymbol{e}} / \boldsymbol{R}_{\boldsymbol{i}}$ & $\begin{array}{c}\text { Crack } \\
\text { length } \\
\boldsymbol{a}[\mathbf{m m}]\end{array}$ & $\begin{array}{c}\boldsymbol{a} / \boldsymbol{t} \\
\left(\boldsymbol{t}=\boldsymbol{R}_{\boldsymbol{e}}-\boldsymbol{R}_{\boldsymbol{i}}\right)\end{array}$ & $\begin{array}{c}\text { Applied } \\
\mathbf{p r e s s u r e} \\
\boldsymbol{p}[\mathbf{M P a}]\end{array}$ \\
\hline 1 & external & 40 & 20 & 2 & 8.2 & 0.41 & 2.27 \\
\hline 2 & internal & 40 & 20 & 2 & 4.8 & 0.24 & 1.89 \\
\hline 3 & external & 50 & 20 & 2.5 & 15.3 & 0.51 & 1.89 \\
\hline 4 & internal & 50 & 20 & 2.5 & 7.4 & 0.25 & 1.99 \\
\hline
\end{tabular}

The models were manufactured from an araldite plate, having a thickness of $5.6 \mathrm{~mm}$. The cracks were saw cut and sharpened at the tip with a razor blade. The photoelastic constant of the model $f_{\sigma}=2.28$ $\mathrm{MPa} /$ fringe was obtained using a disk made of the same photoelastic material loaded radially in compression and having the same thickness as the specimens [21]. In order to apply a uniform pressure on the internal surface of the rings, a simple device was used (Figure 2).

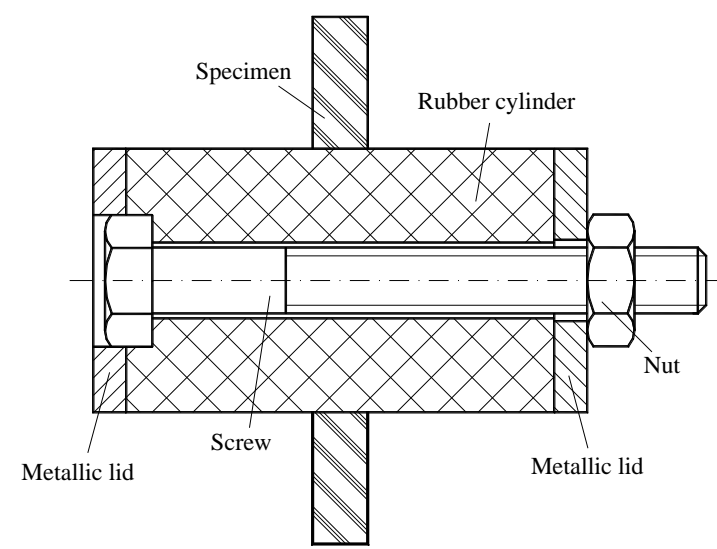

Figure 2: The loading device

The device is made of a rubber cylindrical tube having the external diameter equal to the internal diameter of the model. The tube is compressed longitudinally using a screw - nut system, increasing it's external diameter and applying thus a uniform pressure which causes the opening of the crack in Mode I, [21].

For the stress intensity factor computation, it is necessary to know the value of the internal pressure $p$ in each case. For this, one can use the expressions of the radial and hoop stresses in an uncracked thick walled tube subject to uniform internal pressure:

$$
\sigma_{r}=\frac{R_{i}^{2} p}{R_{e}^{2}-R_{i}^{2}}\left(1-\frac{R_{e}^{2}}{r^{2}}\right), \quad \sigma_{h}=\frac{R_{i}^{2} p}{R_{e}^{2}-R_{i}^{2}}\left(1+\frac{R_{e}^{2}}{r^{2}}\right)
$$

These stresses are the principal ones, which means that, along an isochromatic fringe, the value of $\sigma_{r}-\sigma_{h}$ is constant and equal to $N \cdot f_{\sigma}, N$ being the fringe order. One can determine the fringe order $N$ on a diameter perpendicular to the crack, where the influence of the crack on the isochromatic field is negligible. Taking into account equations (8), one obtains:

$$
\sigma_{1}-\sigma_{2}=\sigma_{h}-\sigma_{r}=\frac{R_{i}^{2} p}{R_{e}^{2}-R_{i}^{2}} \cdot \frac{2 R_{e}^{2}}{r_{N}}=N \cdot f_{\sigma}
$$

where $r_{N}$ is the radius of a point where the fringe order is $N$. Thus, the expression of the applied internal pressure can be written as

$$
p=\frac{\left(R_{e}^{2}-R_{i}^{2}\right) \cdot r_{N}^{2} \cdot N \cdot f_{\sigma}}{2 R_{i}^{2} R_{e}^{2}}
$$


ACTA UIVERSITATIS CIBINIENSIS - TECHNICAL SERIES

Vol. LXIX 2017

The values of the applied pressure calculated with equation (10) are listed in

Table 1. Pictures of the isochromatic fringes are shown in Figure 3.

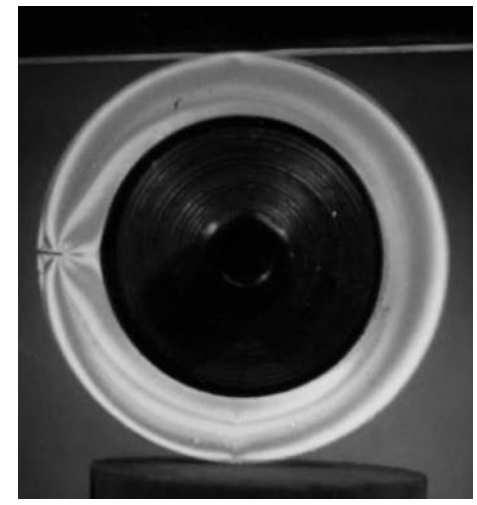

a

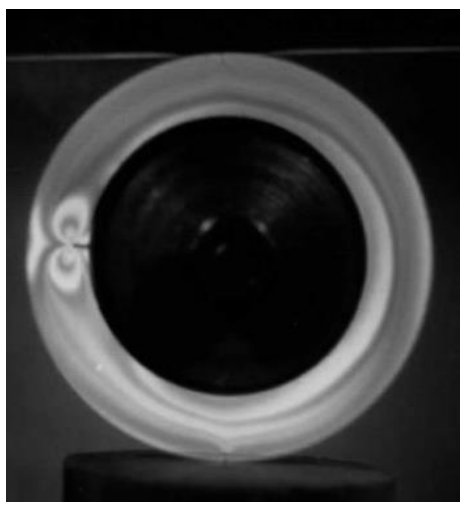

b

Figure 3: Isochromatic fringes for the external crack (a) and internal crack (b)

All models were analyzed in a plane polariscope and the fringe order on a line starting from the crack tip and normal to the crack plane was determined using the Tardy compensation method. In order to compensate the manufacturing errors, measurements were made on both sides of the crack and the results were averaged. It should be underlined that, in the case of the internal crack, the loading device does not apply the pressure also on the crack faces, as it happens in the case of real a cylindrical shell with an internal crack, subjected to internal pressure. This must be taken into account when comparing the obtained results with those of other authors.

\section{Results}

The variation of the normalized apparent stress intensity factor $K_{a p p} / p \sqrt{\pi a}$ versus $\sqrt{r / a}$ is plotted in Figure 4 for all four considered cases. For each case, only the points in the linear area of the graph were considered for extrapolation. These points are marked on the plots with black rhombs, while the points that were discarded are represented as hollow rhombs. In each case, the equation of the linear fit is displayed on the graph. It can be seen that, in all cases, the coefficient of determination $R^{2}$ (goodness of fit) has values between 0.939 and 0.998 , showing thus very small differences between the obtained results and the proposed fit.

In order to check the accuracy of the experimental results, comparison was made with nondimensional SIF values reported by other authors for the same structure.
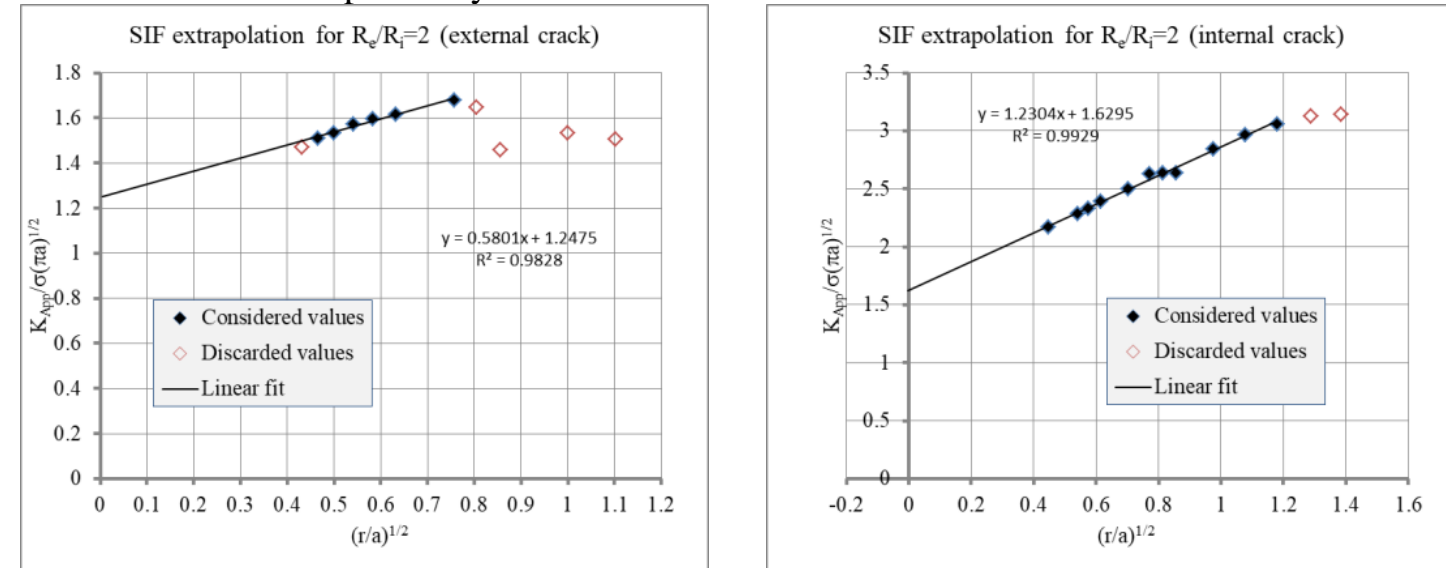
ACTA UIVERSITATIS CIBINIENSIS - TECHNICAL SERIES

Vol. LXIX 2017
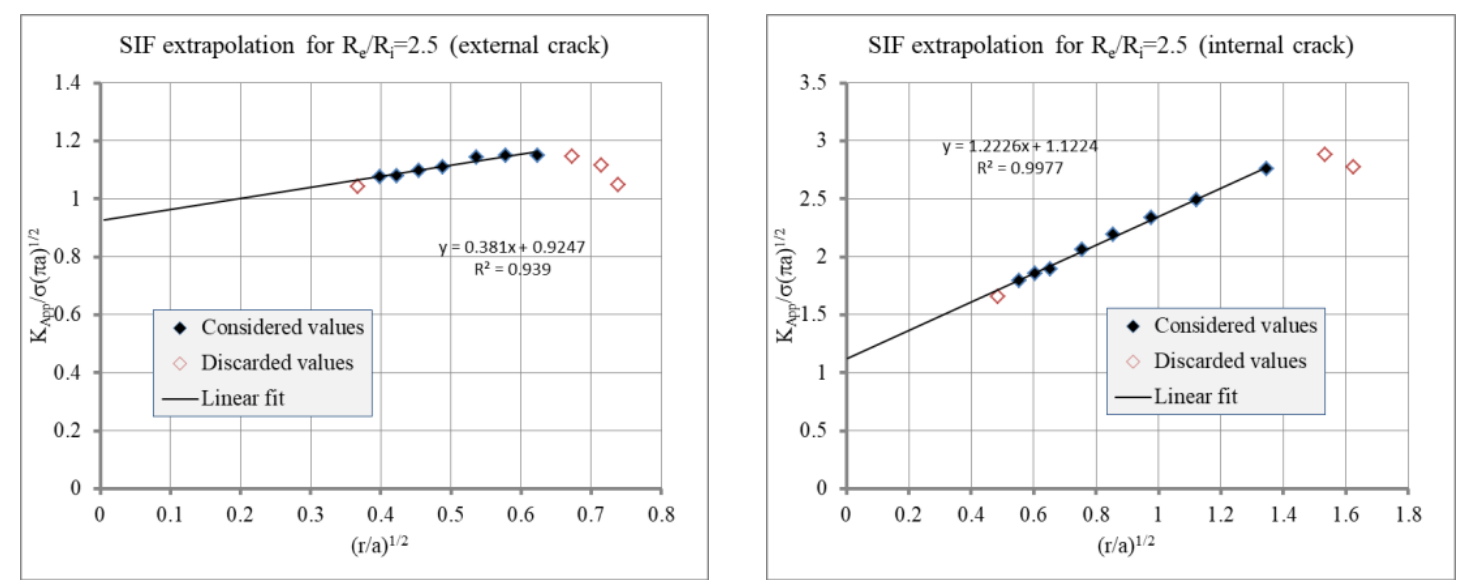

Figure 4: Variation of the non-dimensional stress intensity factors for all studied cases

In the case of an internal crack, a general equation for the normalized stress intensity factor is given by Kendall [22] for a load (internal pressure) acting on both the internal wall and on the crack faces, which is not the case in this research, as mentioned earlier. To obtain the stress intensity value for the case when pressure is applied only on the internal surface of the ring but not on the crack faces, one should find also in the literature values of SIF for a pressure applied only on the crack faces. Then, these values should be subtracted from those obtained using the equation proposed in [22]. Such results were reported by Andrasic and Parker [23] for different $R_{e} / R_{i}$ and $a / t$ ratios. Since the alt values used in the present research are not tabulated in [23], they were obtained by polynomial interpolation. In the case of a single external crack, results are presented by Pastramă and de Castro [24].

The experimental results for all four models, together with similar results reported in [22-24] are given in Table 2. One can notice a very good agreement between the two sets of results, showing a relative error of less than 3\%. In Table 2 are also listed values of the non-dimensional parameter $(r / a)^{1 / 2}$ in which the linear zone of the plot is extended. These values are in good agreement with the predictions from [20].

Table 2- Comparison between the experimental results and those of other authors

\begin{tabular}{|c|c|c|c|c|c|c|}
\hline \multirow{2}{*}{$\mathbf{R}_{\mathbf{e}} / \mathbf{R}_{\mathbf{i}}$} & \multirow{2}{*}{$\mathbf{a} / \mathbf{t}$} & \multirow{2}{*}{ crack type } & \multicolumn{2}{|c|}{$K_{I} / p \sqrt{\pi a}$} & \multirow{2}{*}{$\begin{array}{c}\text { Relative error } \\
{[\%]}\end{array}$} & \multirow{2}{*}{$\begin{array}{l}\text { Extent of the } \\
\text { linear zone }\end{array}$} \\
\hline & & & experimental & [22-24] & & \\
\hline \multirow[t]{2}{*}{2} & 0.41 & external & 1.248 & 1.272 & 1.89 & $(r / a)^{1 / 2} \in(0.36,0.76)$ \\
\hline & 0.24 & internal & 1.63 & 1.595 & -2.19 & $(r / a)^{1 / 2} \in(0.42,1.18)$ \\
\hline \multirow[t]{2}{*}{2.5} & 0.51 & external & 0.925 & 0.901 & -2.66 & $(r / a)^{1 / 2} \in(0.4,0.64)$ \\
\hline & 0.25 & internal & 1.122 & 1.111 & -0.99 & $(r / a)^{1 / 2} \in(0.56,1.36)$ \\
\hline
\end{tabular}

\section{Conclusions}

A photoelastic experiment was undertaken in order to determine the normalized stress intensity factor in a thick walled cylindrical shell subject to a uniform internal pressure and having a straight longitudinal non-penetrating crack. Four plane models, two with an internal crack and two having an external crack, were analyzed. The values of the apparent stress intensity factor for each case were plotted against $\sqrt{r / a}$ and the linear zone was extrapolated at the crack tip. A simple device was used to apply a uniform internal pressure, whose values were determined from photoelastic data collected far from the crack tip. The extent of the linear zone of the graph was determined in each case and compared with the predictions from the literature. The values of the normalized stress intensity factor obtained in this experimental work were compared to those reported by other authors. A good agreement was noticed, showing a difference of less than $3 \%$ between the results. One can conclude that the methodology is reliable and can be successfully used for stress intensity factor determination. 


\section{ACTA UIVERSITATIS CIBINIENSIS - TECHNICAL SERIES}

Vol. LXIX 2017

\section{References}

1. J.M. Etheridge, J.W. Dally, A Critical Review of Methods for Determining Stress-Intensity Factors from Isochromatic Fringes, Experimental Mechanics, Vol. 17, No. 7, pp. 248-254, (1977).

2. G.R. Irwin, Analysis of Stresses and Strains Near the End of a Crack Traversing a Plate, Journal of Applied Mechanics, Vol. 24, pp. 361-364, (1957).

3. W.B. Bradley, A.S. Kobayashi, An Investigation of Propagating Cracks by Dynamic Photoelasticity, Experimental Mechanics, Vol. 10, No. 3, pp. 106-113, (1970).

4. M.A. Schroedel, C.W. Smith, Local Stresses Near Deep Surface Flaws Under Cylindrical Bonding Fields, in Progress in Flaw Growth and Fracture Toughness Testing, ASTM STP 536, ATM, pp. 45-63, (1973).

5. C.W. Smith, Stress Intensity and Flaw-shape Variations in Surface Flaws, Experimental Mechanics, Vol. 20, No. 4, pp 126-133, (1980).

6. J.M. Etheridge, J.W. Dally, A Three Parameter Method for Determining Stress Intensity Factors from Isochromatic Fringe Loops, Journal of Strain Analysis, Vol. 13, No. 2, pp. 91-94, (1978).

7. R. Chona, G.R. Irwin, R.J. Sanford, Influence of the Specimen Size and Shape on the Singularity-Dominated Zone, in Fracture Mechanics: $14^{\text {th }}$ Symposium - Volume I: Theory and Analysis, ASTM STP 868 , J.C. Lewis and G. Sines, Eds., American Society for Testing and Materials, pp. I3-I23, (1983).

8. R.J. Sanford, J.W. Dally, A General Method for Determining Mixed-Mode Stress Intensity Factors from Isochromatic Fringe Patterns, Engineering Fracture Mechanics, Vol. 11, No. 4, pp. 621-633, (1979).

9. R.J. Sanford, Application of the Least-Squares Method to Photoelastic Analysis, Experimental Mechanics, Vol. 20, No. 6, pp. 192-197, (1980).

10. R.J. Sanford, Determining Fracture Mechanics Parameters with Full-Field Optical Methods, Experimental Mechanics, Vol. 29, No. 3, pp. 241-247, (1989).

11. R.J. Sanford, The Influence of Non-singular Stresses on Experimental Measurements of the Stress Intensity Factor, in Modeling Problems in Crack Tip Mechanics - $10^{\text {th }}$ International Conference on Fracture Mechanics, Waterloo, Canada, August 24-26, pp. 317-323, (1983).

12. T.H. Hyde, N.A. Warrior, An Improved Method for the Determination of Photoelastic Stress Intensity Factors Using the Westergaard Stress Function, International Journal of Mechanical Science, Vol. 32, No. 3, pp. 265-273, (1990).

13. M. Mahinfalah, L. Zackery, Photoelastic Determination of Mixed Mode Stress Intensity Factors for Sharp Re-entrant Corners, Engineering Fracture Mechanics, Vol. 52, No. 4, pp. 639-645, (1995).

14. L. Stepanova, P. Roslyakov, P. Lomakov, A Photoelastic Study for Multiparametric Analysis of the Near Crack Tip Stress Field Under Mixed Mode Loading, Procedia Structural Integrity, Vol. 2, pp.1797-1804, (2016).

15. P. Patil, C.P. Vyasarayani, M. Ramji, Linear least squares approach for evaluating crack tip fracture parameters using isochromatic and isoclinic data from digital photoelasticity, Optics and Lasers in Engineering, Vol. 93, pp.182-194, (2017).

16. E. Umezaki, K. Kodamaand, A. Shimamoto, Evaluating the Stress Intensity Factor Using White Light Photoelastic Experiment, Metals and Materials International, Vol. 7, No. 1, pp. 49-53, (2001).

17. A. Cirello, F. Furgiuele, C. Maletta, A. Pasta, Numerical simulations and experimental measurements of the stress intensity factor in perforated plates, Engineering Fracture Mechanics, Vol. 75, No. 15, pp. 4383-4393, (2008).

18. F.A. Diaz, E.A. Patterson, P. Siegmann, A Novel Experimental Approach for Calculating Stress Intensity Factors from Isochromatic Data, Experimental Mechanics, Vol. 50, No. 2, pp. 273-281, (2010).

19. Smith, C.W., Kobayashi, A.S., "Experimental Fracture Mechanics", Ch. 19 of Handbook on Experimental Mechanics, SEM, Inc., A.S. Kobayashi, Ed., Prentice-Hall, Inc., Englewood Cliffs, NJ, pp.891-956, 1987. (1966).

20. C.W. Smith, Cracking at Nozzle Corners in the Nuclear Pressure Vessel Industry, in Case Histories Involving Fatigue and Fracture Mechanics, ASTM STP 918, C.M. Hudson and T.P. Rich, Eds., American Society for Testing and Materials, pp. 31-45, (1986).

21. Pastramă, Ş.D., Contribuţii la studiul tensiunilor şi al factorului de intensitate a tensiunii la învelişuri cu fisuri de suprafaţă (Contributions to the study of the stress field and the stress intensity factor in shells with surface cracks), PhD thesis, University "Politehnica" of Bucharest, (1997) - in Romanian.

22. D.P. Kendall, Stress Intensity Factor Equations for Pressurized Thick Wall Cylinders, International Journal of Fracture, Vol. 30, No. 1, pp. R17-R19, (1986).

23. C.P. Andrasic, A.P. Parker, Dimensionless Stress Intensity Factors for Cracked Thick Cylinders under Polynomial Face Loadings, Engineering Fracture Mechanics, Vol. 19, No. 1, pp. 187-193, (1984).

24. Ş.D. Pastramă, P.M.S. Tavares de Castro, Weight Functions from Finite Element Displacements, International Journal of Pressure Vessels and Piping, Vol. 75, No. 3, pp. 229-236, (1998). 